\title{
MOTOR DEVELOPMENT THROUGH FUNCTIONAL MUSIC THERAPY IN CHILDREN WITH CEREBRAL PALSY
}

\author{
Jiří Kantor \\ Palacký University in Olomouc, Czech Republic
}

\begin{abstract}
This paper presents an analysis of four case studies in order to elaborate the theory of functional music therapy. In the Czech Republic, the practices of functional music therapy are often used as a type of complementary rehabilitation. Although functional music therapy is based on sound and scientifically substantiated bases, practical applications lack comprehensive and systematic methodology. The aim of this paper is to deepen the knowledge of the links between the application of musical practices and functional development. On the basis of an interpretative approach to case studies (using a content analysis) we identified the objectives in the motor area, types of musical activities, and music therapy practices in persons with cerebral palsy. We also analysed the correlation between therapeutic objectives and musical activities, and set out methodological principles of their application. The outcomes of this study were compared with the results of a previous study by the author focusing on persons with severe multiple disabilities in order to develop a comprehensive theory of functional music therapy. Concerning the results of this comparison, this paper discusses the impact of intellectual disability on the flexibility of application of musical activities during functional training.
\end{abstract}

Keywords: Cerebral palsy, functional music therapy, motor functions, multiple disability.

\section{Introduction}

Cerebral palsy (referred to as $\mathrm{CP}$ ) is "an umbrella term used to describe non-progressive disabilities, which manifest as motion or postural abnormalities and result from a CNS lesion during early periods of brain development" (Jacobs, 2001, p. 53). In persons with CP, the difficulties in the motor area represent the core objectives of therapeutic intervention. However, the application of traditional therapeutic methods in persons with $\mathrm{CP}$, for example physiotherapy is complicated by frequent combinations with other types of disorders (Phipps, Roberts, 2012). As a result, rehabilitation requires close interdisciplinary cooperation and communication. Due to the effectiveness of music techniques in functional training, a music therapist is frequently a member of the interdisciplinary team.

The application of music therapy in persons with CP is supported by many research studies. For example, they focus on the influence of music on the muscle tone (Wigram, 1996; Taylor, 2014 and others). In these research studies, music was mostly applied through a receptive form. However, there are 
numerous studies from the area of active music therapy. For example John Bean (1996) developed a series of exercises for the development of targeted movements in children with $\mathrm{CP}$, and with Amelia Oldfield are the authors of musical activities for the development of functional skills (Bean, Oldfield, 2001). Active work is also used by Lasse Hjelm, the author of the FMT method (music therapy focused on the functions of the human body), which is often indicated as a result of motor insufficiencies and is very well applicable in persons with CP (Hjelm, 2015). Another example that shows the positive effects of the application of active musical activities for the development of motor skills in persons with CP is a study by Iranian authors (Hatampour et al., 2011).

For the purposes of functional training some authors modified the traditional musical-educational concepts. Mary Helen Richardson adapted the methodology of Zoltán Kodály for children with health disability, which uses specific techniques facilitating the development of motor skills, e.g. hand signals (Lathom, 1974), other known approaches include the adaptation of the Orff Schulwerk (Darrow, 2008) or Suzuki method.

Other research studies addressed the use of music for patient motivation during physiotherapy and for pain control, which is a big barrier to active movement. Positive effects of music are documented in papers by Olav Skille (1991), Chesky, Russell, Lopes, Kondraske (1997) and other authors or in the summaries of research studies in the monographs by various authors (Peters, 2000).

In the Czech Republic (referred to as the CR) there are many music therapists in the field of education and social services institutions. As is clear from a content analysis of music therapy documents (Kantor et al., 2014), functional objectives are an important component of music therapy practice. On the other hand, however, there seems to be an insufficient conceptual framework in the work of music therapists, which in the CR results from the absence of systematic methodology for functional training. For this reason a number of studies were initiated, whose objective was to develop a theory, according to which it would be possible to elaborate methodological procedures for functional music training.

\section{Research methodology}

The research described in this paper builds on the previously published studies by the author in the field of functional music therapy and also used some previously published methodological procedures (Kantor et al., 2014). The aim of this research study is to analyse the correlations between musical activities and motor objectives of functional training. The difference between this and previous studies lies in the fact that now the research sample includes persons 
with $\mathrm{CP}$, whose functional ability (at least mental functions) are at a higher level.

The research study is based on a qualitative-interpretative analysis of case studies of 4 persons with CP. As stated by Ženka \& Kofron̆ (2012), the aim of the interpretative approach to case studies is not to develop a new theory but rather to interpret the cases according to known theories. Therefore, this paper does not examine effective factors of therapeutic intervention but the way in which music therapy intervention is delivered. The results will be interpreted on the basis of known theories. The main contribution of this is the enrichment of methodological procedures that can be applied in music therapy aimed at persons with CP.

The objectives of the research study are as follows:

- To find out which objectives in the motor area can be addressed by means of musical activities in persons with CP.

- To identify the musical procedures used to achieve the objectives.

- By means of a data analysis to determine whether it is possible to define methodological principles relevant for the delivery of musical activities in order to develop motor skills in persons with CP.

The results of this research study will be compared with the conclusions of a previous study by the author (Kantor et al., 2014) in order to determine the influence of various mental levels of persons with $\mathrm{CP}$ on the delivery of musical activities.

The following criteria were used to form the research sample:

- Persons with CP, but not with severe multiple disabilities or severe mental retardation.

- Music therapy intervention to develop motor functions was carried out for at least six months and was documented.

The research sample included two boys and two girls.

Case 1: Monitoring of the course of five years of music therapy, which was delivered primarily through teaching piano playing. Music therapy began when the girl was 8 years old. This was a girl with moderate functioning autism, bilateral hemiparesis (severe impairment of the right side), strabismus and an outstanding musical talent.

Case 2: A boy with severe quadriparesis, moderate mental retardation and anarthria. Music therapy lasted for three years (music therapy began when the boy was 6 years old); however, this research monitored only the initial period lasting for about half a year.

Case 3: A boy with diparesis (and with mild impairment of the upper limbs) and with mild mental retardation. We monitored 2 years of music therapy, which focused on the development of motor skills through playing the 
piano combined with rhythmic education and listening activities. Music therapy began when the boy was 7 years old.

Case 4: A girl with severe quadriparesis (severe impairment of the lower limbs), moderate mental retardation, strabismus and severe dysarthria, which allowed very limited communication with the environment. Music therapy was delivered for a period of 4 years and began when the girl was 7 years old. Musical activities focusing on the development of motor functions primarily involved improvised and simple interpretative activities using various rhythmic musical instruments.

Data collection was performed by means of interviews with music therapists, analysis of music therapy documents and analysis of products. These products included songs composed for the individuals by music therapists, and rare audio recordings of some parts of the therapy (in two cases also several minutes of video; however, their poor acoustic quality did not allow a detailed analysis). All relevant data relating to individual cases were collected and transcribed into a written form.

The initial data analysis used a content analysis. Its aim was to identify the data relating to the following:

- Objectives of the music therapy process. From all objectives we isolated and separately analysed those objectives that related to the development of motor skills and those related to the development of musical skills.

- Musical activities that required volitional movement of a person with $\mathrm{CP}$ or those that might have a positive impact on motor skills. The data material includes the description of the nature and course of individual activities.

- Music aspects that characterize the musical expression of persons with $\mathrm{CP}$ (quality of tone, tempo, dynamics, etc.)

For each case we conducted an analysis of the relationships between the development of motor functions, the development of musical skills, course and development of musical activities, and the quality of musical expression. The results of the analysis are presented in the text below. In this way it was possible to describe the relationships between musical activities, their development, objectives in the area of motor skills and specific features of musical expression, which can be used for diagnosis and evaluation. 


\section{Results of analysis of individual cases}

The results are related to individual cases.

\section{Case 1}

The girl in case study 1 had an outstanding musical talent, which allowed her to identify piano song melodies just by ear. At the very beginning (during diagnostic stage) the music therapist revealed that she was not able to work in an improvisatory manner. She needed a clear structure provided by the music material with a song form. The therapy was performed by means of learning musical skills for playing the songs. Table 1 shows some of the crucial moments in learning musical skills, increasing the complexity of motor objectives and examples of the music material applied.

Table 1 Analysis of the relationships between motor objectives, development of musical skills and music material

\begin{tabular}{|l|l|l|}
\hline $\begin{array}{l}\text { Motor objectives and their } \\
\text { development }\end{array}$ & $\begin{array}{l}\text { Development of musical } \\
\text { skills }\end{array}$ & $\begin{array}{l}\text { Examples of music } \\
\text { material }\end{array}$ \\
\hline $\begin{array}{l}\text { Coordination of two fingers } \\
\text { of LUL }\end{array}$ & $\begin{array}{l}\text { Melody of two to three } \\
\text { tones }\end{array}$ & $\begin{array}{l}\text { Lullabies and nursery } \\
\text { rhymes set to music. }\end{array}$ \\
\hline $\begin{array}{l}\text { Gradual involvement of } \\
\text { other fingers of LUL }\end{array}$ & Melody up to the fifth & $\begin{array}{l}\text { Simple songs, e.g. "Běžela } \\
\text { ovečka", "Lítala si } \\
\text { laštověnka" }\end{array}$ \\
\hline $\begin{array}{l}\text { Coordination of the five } \\
\text { fingers of LUL, thumb } \\
\text { passing under the finger and } \\
\text { the hand passing over the } \\
\text { thumb }\end{array}$ & $\begin{array}{l}\text { Melody up to the sixth and } \\
\text { more }\end{array}$ & $\begin{array}{l}\text { Simple songs, e.g. "Skákal } \\
\text { pes" }\end{array}$ \\
\hline $\begin{array}{l}\text { Playing with one finger } \\
\text { (index finger) of RUL }\end{array}$ & $\begin{array}{l}\text { Playing a melody with one } \\
\text { finger }\end{array}$ & $\begin{array}{l}\text { Reproduction of learned } \\
\text { melodies, adding other } \\
\text { melodies }\end{array}$ \\
\hline $\begin{array}{l}\text { The same in coordination } \\
\text { with RUL }\end{array}$ & $\begin{array}{l}\text { Playing the bourdon (bass) } \\
\text { as accompaniment }\end{array}$ & $\begin{array}{l}\text { Accompaniment of songs in } \\
\text { C major using bass tones of } \\
\text { Cand G (for harmonic } \\
\text { functions of the keynote and } \\
\text { dominant). }\end{array}$ \\
\hline $\begin{array}{l}\text { Gradual adding of fingers of } \\
\text { RUL in coordination with } \\
\text { LUL }\end{array}$ & $\begin{array}{l}\text { Playing songs with a small } \\
\text { melody range and chordal } \\
\text { accompaniment }\end{array}$ & $\begin{array}{l}\text { Songs with chordal } \\
\text { accompaniment } \\
\text { harmonic functions of the } \\
\text { keynote and dominant. }\end{array}$ \\
\hline $\begin{array}{l}\text { Playing with several fingers } \\
\text { of LUL at the same time } \\
\text { (difficult chords in terms of } \\
\text { motor skills) }\end{array}$ & $\begin{array}{l}\text { Teaching chords and their } \\
\text { shifts }\end{array}$ & $\begin{array}{l}\text { Various songs, at the } \\
\text { beginning, accompanied by } \\
\text { cadence, gradual adding of } \\
\text { other chords. }\end{array}$ \\
\hline
\end{tabular}


Jiři Kantor. Motor Development Through Functional Music Therapy in Children with Cerebral Palsy

\begin{tabular}{|l|l|l|}
\hline $\begin{array}{l}\text { Increasing the movement } \\
\text { range on the keyboard }\end{array}$ & $\begin{array}{l}\text { Adding semitone keys and } \\
\text { playing in various keys }\end{array}$ & $\begin{array}{l}\text { The first practice songs } \\
\text { included the keys of G } \\
\text { major, A minor, D major, F } \\
\text { major, etc. }\end{array}$ \\
\hline
\end{tabular}

Note: throughout the whole text, the abbreviation of UL means upper limb, LUL left upper limb and RUL right upper limb.

In terms of musical means of expression the following was monitored:

- $\quad$ Range of movement, including e.g. the ability to stretch the fingers of one UL.

- $\quad$ Strength of movement, including e.g. the dynamics of individual tones and chords (as a result of insufficient muscle strength in her little finger of RUL, the girl made typical movements of the whole hand, so the movement was not primarily based on the little finger, but rather the whole hand).

- Speed of movements, which affected the tempo of the songs.

- Coordination of the movements of a single hand, for example coordination of the fingers when playing chords, and coordination of both UL during chordal accompaniment of a song melody.

Regarding the fact that Case 1 provided the largest body of data material, it was possible to use the data to define the basic principles of the methodology of therapy aimed at motor functions of the hands through piano playing.

\section{Case 2}

In Case 2 the possibilities of engaging the boy in musical activities were strongly limited by the severe mobility and communication impairment. At the beginning of therapy the boy's mental level was undervalued as a result of limited diagnosing possibilities (also as a result of anxiety and slow adaptation to the school environment).

The priority area for music therapy defined at the beginning was non-verbal communication because it was necessary to train at least basic movements to allow simple yes/no communication. These communication signals were performed by means of head movements to the sides and up and down. First we used stimulation by listening to various sounds, then simple exercises with an encouragement to move the head down as instructed in the song. The song was composed by the music therapist directly for the boy.

After achieving a better control of head movements, the attention of music therapy shifted to the mobility of the upper limbs. For the boy it was important to improve the controlled movements of the upper limbs (their mobility was of approximately the same level) to facilitate communication, which was performed by selecting photographs or pictograms. Regarding the boy's musical 
preferences this was performed by assisted guitar playing. At the beginning of training, the whole UL and palms were relaxed (stretching the fingers against the top resonant body of the guitar). After that, playing was practised in an effort to sound the strings (by means of one or both upper limbs). The music therapist played chords on the guitar and accompanied by singing. The music therapist held the guitar in a position accessible for the boy concerning his limited range of movement.

At the end of the first six months we observed greater motor control over the movements:

- Quicker opening and releasing of the palm from a spastic hold.

- Greater speed of movements for sounding the strings, which allowed continuous accompaniment of certain sections of trained songs.

However, the progress was negatively affected by frequent performance fluctuations and was apparent only in some situations (motor performance was affected by frequent fatigue, overall tension, etc.) After the first six months, music therapy with the boy continued but focused on other objectives.

\section{Case 3}

Case 3 included a boy with perinatal complications and significantly unbalanced development. The objective of music therapy in this case was to train motor, perception and cognitive functions. Music therapy primarily included playing the keyboard with complementary rhythmic education (training of perception and cognitive functions) and listening activities in order to increase the motivation for exercise. At the beginning, teaching the keyboard was conducted by means of common piano school methods (with minor adjustments to the methodological procedures). During the first six months the boy acquired basic skills to orientate on the keyboard and to coordinate the movements when playing with a single upper limb, including thumb passing under the finger and the hand passing over the thumb. The acquisition of musical skills was considerably slower compared with intact peers. The therapy was complemented with an exercise of reproducing simple rhythmic structures.

Greater problems were encountered in practising tunes that required reading notes and coordination of both upper limbs. Usual note scores were difficult to comprehend for the boy; there were also problems in practising the use of alternative forms of notation. The boy was able to musically reproduce only those tunes that were short and easy to remember (e.g. melodies of simple folk songs). This fact was reflected in the course of therapy. The therapy continued with practising folk songs with simple chordal accompaniment.

During the second year the therapist began to create variations of the accompaniment to facilitate the reproduction of songs, practise coordination of motor functions and increase the aesthetic level of musical expression. The keys were provided with various audio functions for bass accompaniment (such as the 

Palsy

sound of the organ) so it was possible to accompany the songs not through chordal accompaniment, but through a simple progression of the bass line. In this way, it was possible for the boy to learn songs that were more difficult in terms of harmonic accompaniment. The connection of the melody line of the song played with the right hand and the accompaniment of the bass line was used for training the coordination of the movements of UL.

At the end of the second year a new method was effectively incorporated into the work procedure. The boy began to compose simple melodies, for which the therapist composed the accompaniment, including alternative note scores for the accompaniment. The boy recorded his own production of the songs and then played the recordings to his family members, classmates, teachers, etc.

\section{Case 4}

The fourth case included a girl with quadriparesis combined with athetosis movements. At the beginning of therapy, mobility of UL allowed her to grasp objects with one hand (the left side of the body was more impaired). Music therapy was conducted by means of creating structured exercises aimed at training various motor functions. Initially, this was any physical activity allowing the girl to sound an instrument and accompany a song, e.g. playing the cymbal or drum (with a stick), playing the tambourine resting on her lap, etc. Emphasis was placed on motivation for and confidence in her movement.

During the fifth month of music therapy, basic prerequisites were created for training through more difficult activities. Parallel training was carried out focusing of grasping functions and extending the range of movement of the right UL. Similar exercises (with less intensity) were performed by the left UL in order to prepare for coordinated movement using both UL. The training of movements included flexion and extension of the elbow, abduction of the shoulder and extension of the elbow (playing the drum positioned on the side of the body), horizontal flexion of the shoulder joint (movement into the transverse crossing), elevation of the shoulder and supination of the forearm. The girl managed to perform individual movements but had problems with extreme positions of certain movements, especially elevation of the shoulder. She also had a problem with decreased muscle strength and accuracy of movements, which was apparent in the dynamics and quality of the sound.

The instruments used included primarily the drum (accompaniment by means of a stick, drum positioned on a stand in an open space). The girl was able to create a rhythmic pulse, while the therapist accompanied her on the guitar at her pace. It was also possible to complement the drum with other instruments (cymbal and other drums) and create simple drum sets. This increased the range of movements in space, e.g. when setting the height of the instruments, various distances of the instruments from the body, etc. These exercises focused on the accuracy of movements. 
In terms of grasping functions the exercises focused on the tweezers grasp (e.g. holding a piece of string with bells and jingle bells attached) and persistence of the cylinder grasp (so that the girl is able to hold a stick throughout the whole song). In terms of training the cylinder grasp an effective way was to use sticks of various diameters, which was achieved by using different sleeves (including ergonomic sleeves for holding pens and pencils, which are used with persons with spastic hold).

During the second year it was necessary to increase the control over the movements of the fingers of UL to improve self-care. A song was composed for the girl, during which she showed various shapes by her hand (fists, open palms), and when the names of fingers were pronounced she caught them with the more movable upper limb.

At the beginning of the third year of music therapy an objective was defined to support the coordination of both UL. Until then the girl was able to use the less movable left UL only to hold some objects (in this way she played the tambourine, which she usually held resting against the side of the orthopaedic wheelchair or on the lap). This objective was significant also due to the fact that at this time the school began training independent control of the orthopaedic wheelchair, which was difficult for the girl due to worse control of movements and lower muscle strength in LUL.

The stages and the sequence of the development of the coordination functions are shown in Table 2. At first, music therapy focused on the training of the coordination functions by means of holding the instrument with the left UL, after that by means of parallel movements, alternating movements and independent movements. In the course of therapy the girl also trained various qualitative and performance aspects of movement. By means of intentional positioning of the instrument in space, selection of the instrument, selection of the tempo and dynamics of accompaniment, adding additional verses, etc. it was possible to train speed, strength, persistence, coordination, range and accuracy of movements.

Table 2 Stages of training the coordination of the upper limbs

\begin{tabular}{|l|l|l|l|}
\hline Stage & $\begin{array}{l}\text { Characteristic } \\
\text { movements }\end{array}$ & $\begin{array}{l}\text { Examples of musical } \\
\text { activities }\end{array}$ & $\begin{array}{l}\text { Specific requirements } \\
\text { for musical skills }\end{array}$ \\
\hline 1. & $\begin{array}{l}\text { Playing and holding the } \\
\text { instrument with the less } \\
\text { movable UL }\end{array}$ & $\begin{array}{l}\text { Playing the tambourine, } \\
\text { rhythm sticks, small drum } \\
\text { (sounding with a stick or } \\
\text { palm), small cymbals. }\end{array}$ & - \\
\hline 2. & Parallel movements & $\begin{array}{l}\text { Playing the African } \\
\text { drums or a set of } \\
\text { instruments (e.g. drum } \\
\text { and cymbal). }\end{array}$ & $\begin{array}{l}\text { Ability to develop a } \\
\text { rhythmic pulse. }\end{array}$ \\
\hline
\end{tabular}


Jiři Kantor. Motor Development Through Functional Music Therapy in Children with Cerebral Palsy

\begin{tabular}{|l|l|l|l|}
\hline 3. & Alternating movements & $\begin{array}{l}\text { Similar musical activities } \\
\text { as in parallel movements. }\end{array}$ & $\begin{array}{l}\text { Ability to develop a } \\
\text { rhythmic pulse. }\end{array}$ \\
\hline 4. & Independent movements & $\begin{array}{l}\text { Practising the African } \\
\text { drum or a set of } \\
\text { instruments as in the } \\
\text { previous case. }\end{array}$ & $\begin{array}{l}\text { Combination } \\
\text { accented and unaccented } \\
\text { beats according to } \\
\text { various movements of } \\
\text { UL, for example playing } \\
\text { a rhythmic pulse by one } \\
\text { UL combined with } \\
\text { accented beats played by } \\
\text { the other UL. }\end{array}$ \\
\hline
\end{tabular}

\section{Discussion}

The answers to the research questions are detailed below and are based on an analysis of data material concerning the case studies:

First objective: Musical activities in persons with $\mathrm{CP}$ focused on the following objectives - mobility of the whole UL (range, speed, strength, accuracy and persistence of movements), motor functions of the palm and fingers, coordination of UL and the development of the functions controlling head movements. A total of four stages were developed for the coordination of the movements of the upper limb.

Second objective: The above defined musical objectives were linked with the following musical activities - teaching piano playing according to specifically adapted methodologies ( 2 cases), assisted guitar playing, songs with encouragement to control head movements, and activities including rhythmic instruments.

In most cases the music material included songs and instrumental accompaniment. The therapists used original songs (mostly folk songs with simple melodies and simple musical form, but also artificial songs or songs composed by the therapist). In the third case there were attempts to compose own musical fragments. The music therapy methods included primarily interpretation and composition.

Third objective: In terms of methodological principles the paper described specifically developed methods for playing the piano (Case 1) and for the development of coordination of UL (Case 4).

The findings of the present survey provided a body of data, which were compared with a previous research study by the author. This research study included persons with severe multiple disabilities. The comparison was performed by means of searching for agreements and disagreements in the data material in order to identify the methodological procedures for persons with milder degrees of multiple disabilities. The conclusions defined in the paper 
relate to the impact of the level of mental functions on the characteristics of the music therapy process. Significant differences were identified in the following areas:

Applied methods and the design of musical activities - a higher mental level allows the use of e.g. composition or interpretive methods, which are difficult to apply in the case of persons with severe mental retardation (here music therapy intervention relies primarily on music improvisation).

Course of intervention - at the beginning of music therapy it is necessary to establish an interaction in a musical context, in persons with severe multiple disabilities this stage can take quite a long time (some authors mention months of therapy, e.g. Drlíčková, 2012). In groups of persons with milder mental disabilities the intervention takes place in a different context, the procedures that the therapist intends to use can be explained, the purpose of intervention can be explained, etc. The therapeutic process is more diverse.

Music products - music products created by persons with severe multiple disabilities are less complex, their musical analysis is too plain to have sufficient response relevance concerning the content of the music product from a musical viewpoint.

\section{Conclusion}

The paper used an interpretative content analysis and analysis of case studies to identify the musical activities used for the development of motor objectives in persons with $\mathrm{CP}$, and to describe some differences in the intervention, which are caused by various mental levels of persons with $\mathrm{CP}$ (comparison of severe mental disability with milder degrees of limited mental functions). The outcomes of this research study were compared with the conclusions of previous studies by the author, and incorporated into the currently emerging theory of functional music training, which will be used to design music therapy practices.

\section{The research in this paper was supported by the dean grant project of the Faculty of Education, the University of Palacký in Olomouc (for the year 2016).}

\section{References}

Bean, J. (1986). Music Therapy Techniques with the Cerebral-Palsied Child for Developing Voluntary Motor Control. British Journal for Music Therapy. 1987; 1: 1/66-72.

Bean, J., \& Oldfield, A. (2001). Pied Pieper: Musical Activities to Develop Basic Skills. (2 ${ }^{\text {nd }}$ ed.). London: Jessica Kingsley Publishers.

Chesky, K. S., Russell, I. J., Lopes, Y., \& Kondraske, G. (1997). Fibromyalgia tender point pain: a double-blind, placebo-controlled pilot study of music vibration using the Music Vibration Table. Journal of Musculoskeletal Pain. 1997; 5: 2/22-52. 
Jiři Kantor. Motor Development Through Functional Music Therapy in Children with Cerebral Palsy

Darrow, A. A. (2008). Introduction to Approaches in Music Therapy. (2 ${ }^{\text {nd }}$ ed.). Silver Spring: American Music Therapy Association.

Drlíčková, S. (2012). Reflexe muzikoterapeutického modelu a jeho aplikace u klienti̊ s kombinovaným postižením. (Bakalářská práce). Olomouc: Univerzita Palackého v Olomouci (Pedagogická fakulta).

Hatampour, R. et al. (2011). The effects of music therapy on sensory motor functions of multiple handicapped people: Case study. Procedia - Social And Behavioral Sciences. 2011; 1: 2011/1124-1126.

Hjelm, A. (2015). FMT - Functionally oriented music therapy. Retrieved from WWW: http://www.fmt-metoden.se/fmtsiteng/index.html

Jacobs, J. (2001). Management options for the child with spastic cerebral palsy. Orthopaedic Nursing. 2001; 20: 3/53-61.

Kantor, J. et al. (2014). Kreativní přistupy v rehabilitaci osob s těžkým kombinovaným postiženim. ( $1^{\text {st }}$ ed.). Olomouc: Vydavatelství Univerzity Palackého.

Lathom, W. (1974). Application of Kodály Concepts in Music Therapy. Journal of Music Therapy. 1974; 11: 1/13-20.

Peters, J. (2000). Music Therapy: An Introduction. ( $2^{\text {nd }}$ ed.). Charles C Thomas Publisher: Springfield.

Phipps, S., \& Roberts, P. (2012). Predicting the Effects of Cerebral Palsy Severity on SelfCare, Mobility, and Social Function. The American Journal of Occupational Therapy. 2012; 66: 4/422-429.

Skille, O. (1991). Vibroacoustic Manual. Levanger: Trilax Center. Cit. 2.1.2005. Online. Retrieved from WWW: http://members.tripod.com/ quadrillo/VAT/e_manual-2.html

Taylor, D. B. (2014). Biomedical Foundations of Music as Therapy. ( $2^{\text {nd }}$ ed.). Wisconsin Barton Publications.

Wigram, T. (1996). The Effects of Vibroacoustic Therapy on Clinical and Non-clinical Population. (Dizertační práce). London: London University (St. George's Medical Hospital School). $290 \mathrm{~s}$.

Ženka, J., \& Kofroň, J. (2012). Metodologie výzkumu v sociální geografii-př́padové studie. $\left(1^{\text {st }}\right.$ ed.). Ostrava: Ostravská univerzita. 